\title{
Percutaneous endoscopic colostomy: a useful technique when surgery is not an option
}

\author{
Gloria Tun, Dominic Bullas, Ayman Bannaga, Elmuhtady M. Said
}

Barnsley Hospital NHS Foundation Trust, South Yorkshire, UK

\begin{abstract}
Percutaneous endoscopic colostomy (PEC) is a minimally invasive endoscopic procedure that offers an alternative treatment for high-risk patients with sigmoid volvulus or intestinal pseudoobstruction who have tried conventional treatment options without success or those who are unfit for surgery. The procedure acts as an irrigation or decompressing channel and provides colonic 'fixation' to the anterior abdominal wall. The risk of complications highlights the importance of informed consent for patients and relatives.
\end{abstract}

Keywords Colostomy, volvulus, intestinal pseudo-obstruction

Ann Gastroenterol 2016; 29 (3): 1-4

\section{Introduction}

Percutaneous endoscopic colostomy (PEC) is a minimally invasive procedure usually recommended for high-risk patients not candidate for surgical intervention as an alternative. The procedure was first described in 1986. Since then it has been more widely practiced although there is scarce literature regarding technique, efficacy and safety. National Institute of Clinical Excellence (NICE) latest guidelines were published in 2006. They state "current evidence on the safety and efficacy of PEC appears to be adequate to support it in elderly and frail patients with recurrent sigmoid volvulus and colonic motility problems provided that the normal arrangements are in place for audit and clinical governance" [2]. The procedure acts as an irrigation or decompressing channel or, via direct traction and secondary fibrosis, provides colonic 'fixation' to the anterior abdominal wall [3].

Herein we describe describe 2 case histories to highlight the preparation, method and technique and propose a check list for the procedure (Table 1).

Department of Gastroenterology and Endoscopy, Barnsley Hospital NHS Foundation Trust, South Yorkshire, UK

Conflict of Interest: None

Correspondence to: Dr Elmuhtady M. Said, MB BS, MRCP (I), FRCP (Glasg), FEBGH, Consultant Gastroenterologist, Department of Gastroenterology, Barnsley General Hospital NHS Foundation Trust, Barnsley, S75 2EP, South Yorkshire, UK, Tel.: +44 1226730000 ,

Fax: +44 1226 437215, e-mail: drsaid@doctors.org.uk

Received 18 April 2016; accepted 9 May 2016;

published online 10 June 2016

DOI: http://dx.doi.org/10.20524/aog.2016.0058

\section{Case history 1}

A 75-year-old female with multiple sclerosis was admitted with abdominal pain, distention and diarrhea (Fig. 1A). Following abdominal X-ray (Fig. 2) and surgical review she was diagnosed with intestinal pseudo-obstruction. PEC was recommended to decompress the abdomen and releive the pain. The procedure was performed under light sedation of $2 \mathrm{mg}$ of midazolam. A single dose of intravenous antibiotics was given (amoxicillin and clavulanic acid). The abdomen was prepped with aqueous Betadine.

The colonoscope was introduced to the hepatic flexure and then withdrawn to the level of proximal descending colon. Trans-illumination was performed with the lighted tip of the endoscope pressing outward against the abdominal wall to identify point of insertion. Local anesthetic was infiltrated into the skin and the sheath. Using the percutaneous endoscopic gastrostomy (PEG) kit, a needle was used to enter the colon under direct vision. The wire was grasped by a snare (Fig. 3). A 20-Fr PEG tube was then pulled and trailed into the colon and out through the abdominal wall (Ponsky technique). The position was checked by reinsertion of the colonoscope (Fig. 4).

\section{Case history 2}

A 91-year-old male was admitted with abdominal pain and distention (Fig. 5A). Computed tomography scan of the abdomen (CT) confirmed sigmoid volvulus (Fig. 6). The patient was deemed not fit for surgery (sigmiodoplexy) and PEC recommended to fix and decompress the colon. Initial preparations were similar to case 1 . 


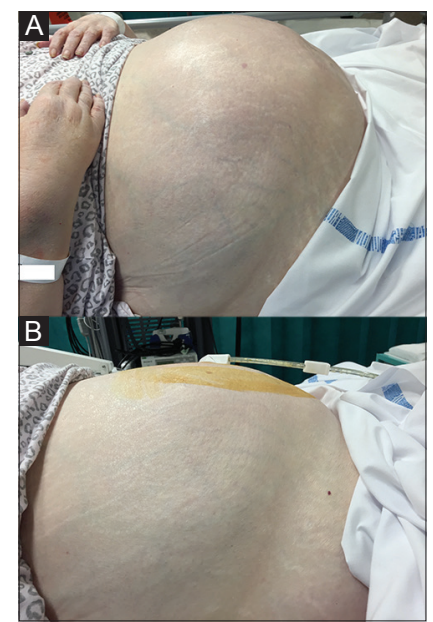

Figure 1 (A) Abdominal distension in intestinal pseudo obstruction. (B) Percutaneous endoscopic colostomy is inserted in one position to facilitate decompression

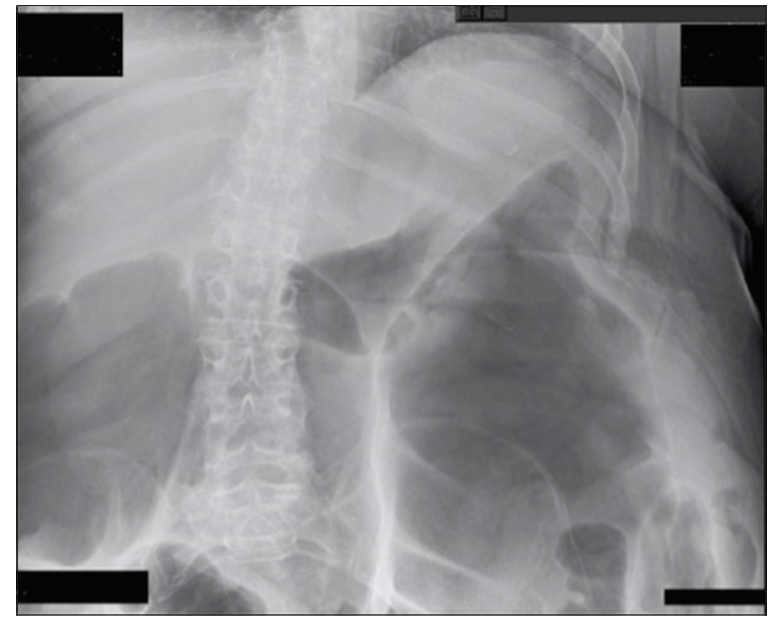

Figure 2 Abdominal X-ray: Distended bowel loops in intestinal pseudo obstruction

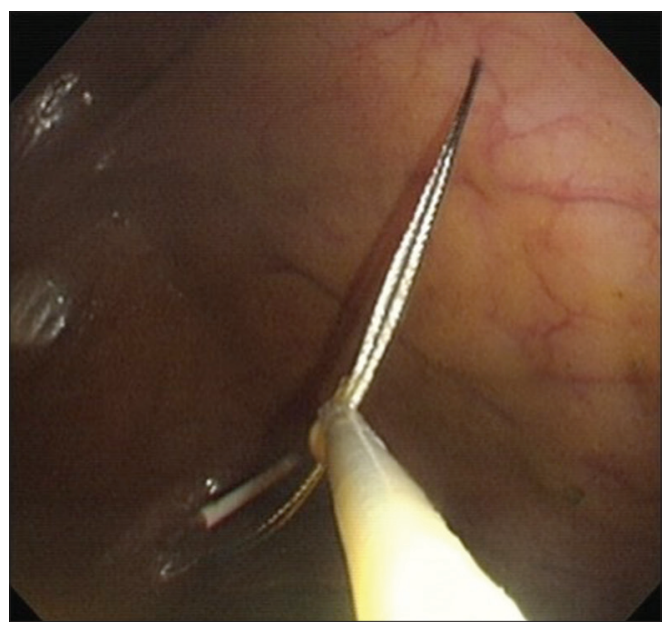

Figure 3 The wire was grasped by a snare

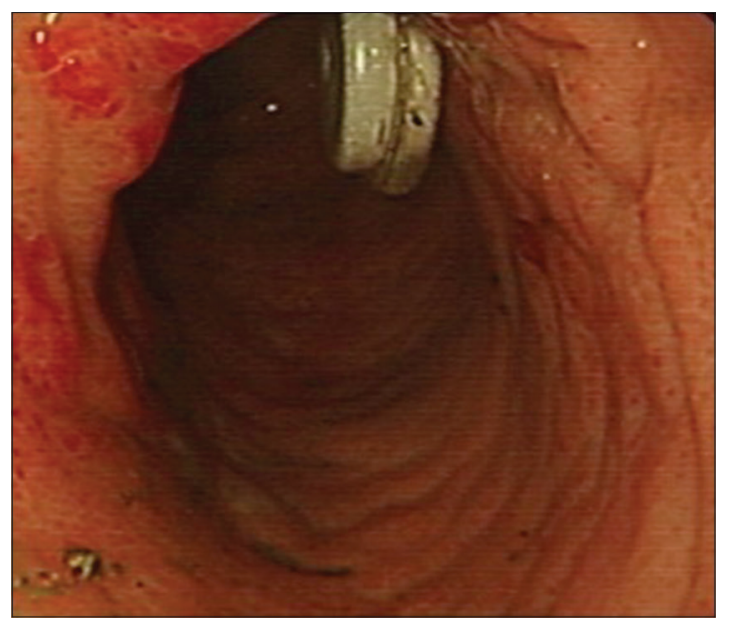

Figure 4 The position was checked with the colonoscope

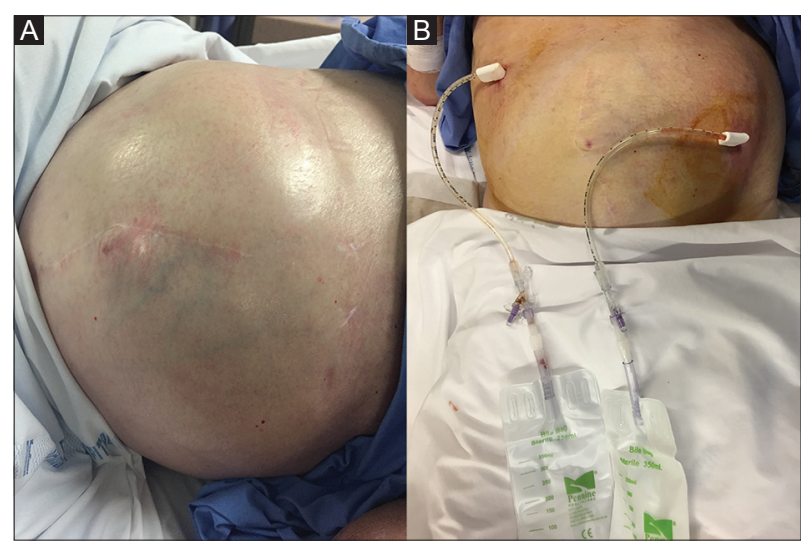

Figure 5 (A) Abdominal distension in sigmoid volvulus. (B) Percutaneous endoscopic colostomy inserted in 2 positions to fix the colon and prevent further twisting

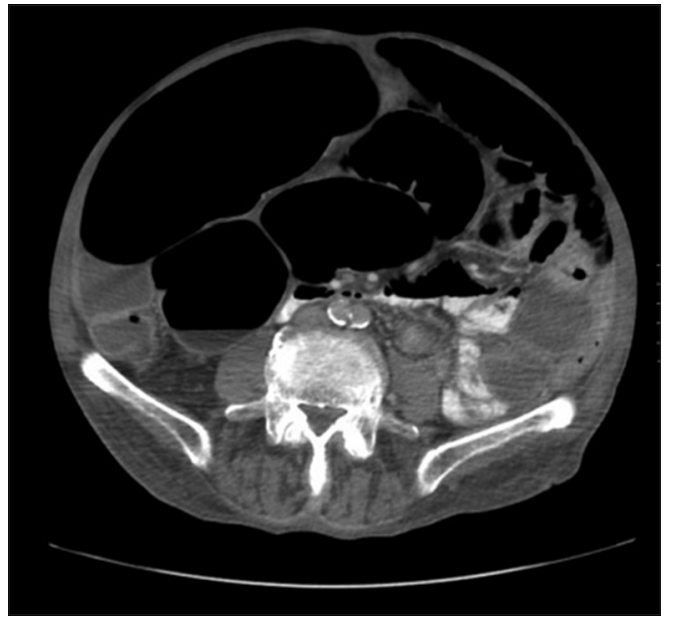

Figure 6 Computed tomography scan abdomen of sigmoid volvulus

The colonoscope was introduced to the ascending colon then withdrawn to proximal limb of the volvulus (Fig. 7). 


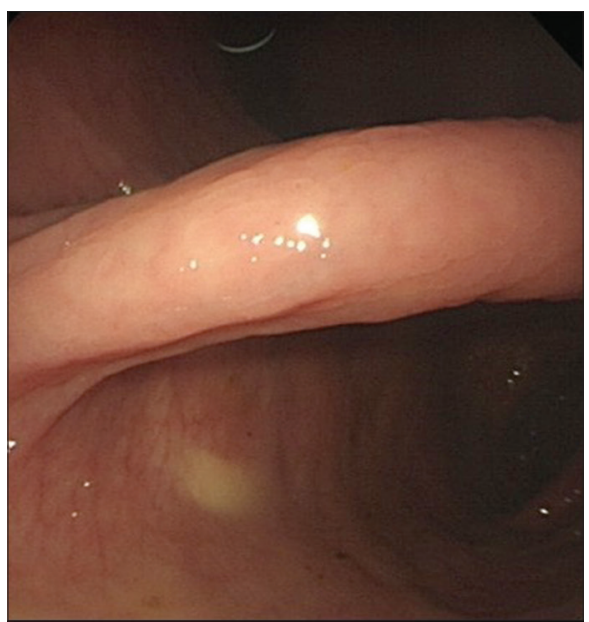

Figure 7 The two limbs of sigmoid volvulus

Table 1 Percutaneous endoscopic colostomy checklist

\begin{tabular}{|c|c|}
\hline \multirow[t]{2}{*}{ Indication } & Ascertain indication, define outcome \\
\hline & Ensure no contraindication \\
\hline \multirow[t]{2}{*}{ Consent } & $\begin{array}{l}\text { Patient may be unable to consent, } \\
\text { Discuss with family/carer }\end{array}$ \\
\hline & discuss with colorectal surgeon \\
\hline Review images & AXR or CT abdomen \\
\hline \multirow[t]{2}{*}{ Bowel Prep } & $\begin{array}{l}\text { Difficult to achieve complete bowel } \\
\text { cleansing. }\end{array}$ \\
\hline & Phosphate enema \\
\hline \multirow[t]{3}{*}{ Medication } & Light sedation (1-2 mg midazolam) \\
\hline & $\begin{array}{l}\text { Pre-procedure antibiotics (amoxicillin } \\
\text { and clavulanic acid /metronidazole) }\end{array}$ \\
\hline & Post-procedure antibiotics for 5 days \\
\hline PEG kit & 20-Fr tube \\
\hline \multirow[t]{3}{*}{ Select PEC position } & 2 positions for sigmoid volvulus \\
\hline & 1 position for all other indications \\
\hline & $\begin{array}{l}\text { Use finger indentation, } \\
\text { transillumination }\end{array}$ \\
\hline Local anesthetics & Lignocaine $1 \%$ \\
\hline Check position & Re-insert the scope \\
\hline \multirow[t]{4}{*}{ Post procedure } & $\begin{array}{l}\text { Never clamp the tube to ensure } \\
\text { continuous venting/decompression }\end{array}$ \\
\hline & Regular Flushing to prevent blockage \\
\hline & Patient/carer education \\
\hline & Watch for complications \\
\hline
\end{tabular}

AXR, abdominal X-ray; CT, computed tomography; PEG, percutaneous endoscopic gastrostomy; PEC, percutaneous endoscopic colostomy

Transillumination was performed to identify the first point of insertion. Local anesthetic was infiltrated into the skin and the sheath. A 20-Fr PEG tube was then pulled and trailed into the colon, through the abdominal wall (Ponsky technique).

The colonoscope was further withdrawn to the distal limb of the volvulus. Transillumination was performed to identify the second point of insertion. Another 20-Fr PEG tube was inserted through the abdominal wall.

\section{Discussion}

PEC offers an alternative treatment for high-risk patients who have tried conventional treatment options without success or those who are unfit for surgery. Indications for the procedure include: fixation of the colon in recurrent sigmoid volvulus [4]; intermittent or continuous decompression of colonic pseudoobstruction/megacolon [5]; and antegrade distal colonic and rectal irrigation/enema in some cases of evacuatory disorder or constipation not responding to other treatment options [6].

There is no clear guideline about the number of PECs to be inserted per individual. For patients with sigmoid volvulus, we recommend that the PEC is inserted in two locations, preferably on both limbs of the volvulus to fix the colon and prevent further "twisting" of the bowel (Fig. 5B). For patients with all other indications, a PEC is inserted in one position, proximal left colon, to provide irrigation or decompressing channel (Fig. 1B).

Contraindications include: failure of transillumination; anterior abdominal infection and sepsis; colonic ischemia; and mechanical intestinal obstruction. Patients and/or their parents should be fully informed about the potential risk of peritonitis, the most serious complication associated with PEC [7-9]. This carries significant mortality as the patients for whom the procedure is used for are often elderly and frail and, in most, deemed unfit for surgery. The risk of complications can be as high as $42 \%$ [7] and range from local infection, pain at PEC site, PEC leakage, granuloma formation, buried internal bolster, and tube erosion [2,7-9]. Local infections, if not responsive to conservative treatment with antibiotics may need removal of the PEC tube. Delayed complications can occur with one case report described peritonitis 2 months after PEC insertion due to traction injury to the bowel wall leaving a hole in the colon, which allowed fecal spillage [7].

The risk of complications highlights the importance of informed consent for patients and relatives. However, despite the risk of complications, PEC offers an effective treatment option for patients who otherwise would require repeat hospital admissions, multiple endoscopic decompressions (in the case of sigmoid volvulus) and in whom the conditions themselves and surgery carry significant mortality.

\section{References}

1. Ponsky J, Aszodi A, Perse D. Percutaneous endoscopic cecostomy: a new approach to nonobstructive colonic dilation. Gastrointest Endosc 1986;32:108-111.

2. National Institute of Clinical Excellence; Interventional procedure guidance (IPG). Percutaneous endoscopic colostomy [Internet]. 2006. Available from: www.nice.org.uk/IPG161

3. Baraza W1, Brown S, McAlindon M, Hurlstone P. Prospective analysis of percutaneous endoscopic colostomy at a tertiary referral 
centre. Br J Surg 2007;94:1415-1420.

4. Daniels IR, Lamperelli MJ, Chave H, Simson JNL. Recrrent sigmoid volvulus treated by percutaneous endoscopic colostomy. Br J Surg 2000;87:1419.

5. Heriot AG, Tilney HS, Simson JNL. Percutaneous endoscopic colostomy for obstructed defaecation. Dis Colon Rectum 2002;45:700-702.

6. Gauderer MW, Decou JM, Boyle JT. Sigmoid irrigation tube for the management of chronic evacuation disorders. J Pediatr Surg 2002;37:348-351.

7. Bertolini D, De Saussure P, Chilcott M, Girardin M,
Dumonceau JM. Severe delayed complication after percutaneous endoscopic colostomy for chronic intestinal pseudoobstruction: A case report and review of the literature. World $J$ Gastroenterol 2007;13:2255-2257.

8. Khan A, Ullah S, Beckly D, Oppong C. Percutaneous endoscopic colostomy (PEC): an effective alternative in high risk patients with recurrent sigmoid volvulus. J Coll Physicians Surg Pak 2013;23:806-808.

9. Cowlam S, Watson C, Elltringham M, et al. Percutaneous endoscopic colostomy of the left side of the colon. World $J$ Gastroenterol 2007;13:2255-2257. 